\title{
Os sintomas psicofuncionais e as consultas terapêuticas pais/bebê ${ }^{1}$
}

\author{
Elizabeth Batista Pinto \\ Universidade de São Paulo
}

\begin{abstract}
Resumo
Os distúrbios psicofuncionais do bebê e sua relação com a qualidade dos vínculos primários, principalmente com a figura materna, têm sido objeto de estudos e pesquisas visando o diagnóstico e a intervenção precoces. Conceitos teóricos como mutualidade psíquica e mandato transgeracional têm valorizado a influência das representações parentais e principalmente dos aspectos fantasmáticos dos pais na organização psíquica da criança. Neste artigo discute-se a relação entre a presença de distúrbios psicofuncionais no bebê e os padrões de interação pais/bebê, levando-se em conta três eixos: o comportamental, o afetivo e o fantasmático. Por fim, para ilustrar, descreve-se o caso de um bebê com distúrbio de alimentação.
\end{abstract}

Palavras-chave: sintomas; bebê; vínculo; apego; diagnóstico

\begin{abstract}
Baby's psychofunctional symptoms and parents/baby therapeutic consultations. Baby's psychofunctional symptoms are related to the quality of primary attachment, especially with the mother. Several studies and researches in this field have early diagnosis and intervention as their main objective. Theoretical concepts as psychic mutuality and transgenerational mandate have showed the influence of parental representation and specially their phantasmatic aspects in the child psychological organization. This article discusses the relationship between the presence of psychofunctional symptoms in the baby and the parents/baby patterns of interaction analyzing 3 axes: behavioral, affective and phantasmatic, as well as their patterns of attachment. Finally, to illustrate, we describe the case of a baby with eating difficulties.
\end{abstract}

Keywords: symptoms; baby; attachment; diagnosis

$\mathrm{D}$ iscuto neste texto alguns aspectos do desenvolvimento do bebê, principalmente relativos aos distúrbios psicofuncionais que podem aparecer no início de sua vida e, portanto, da construção de seu psiquismo e de sua subjetividade. Procuro também analisar as conexões entre os distúrbios psicofuncionais do bebê e os vínculos primários, principalmente a relação com a figura materna, tendo sempre em consideração as possibilidades de se diagnosticar e intervir precocemente.

O interesse pelos distúrbios psicopatológicos das crianças pequenas e suas relações com os vínculos iniciais tem-se ampliado muito nas últimas décadas e se difundido por meio de vários eventos científicos no Brasil $^{2}$ e no exterior. Temas relacionados têm sido o principal foco de vários estudos, destacando-se aqueles desenvolvidos na Clínica de Psiquiatria Infantil da Universidade de Genebra, sob a coordenação de Bertrand Cramer e, atualmente, sob a de Francisco PalacioEspasa, e no Departamento de Psicopatologia da Criança e da Família da Faculdade de Medicina da Universidade de Paris XIII, em Bobigny, Paris, fundado por Serge Lebovici (falecido em 2000) e, atualmente, sob a regência de MarieRose Moro.
Muitos autores contribuíram para o desenvolvimento desse campo de estudos, desde os clássicos da psicanálise, como Sigmund Freud (1976), Melanie Klein (1923, 1927, 1928, 1929a, 1929b, 1930, 1945, 1952, 1958) e Donald Winnicott (1931, 1941, 1942, 1945, 1953, 1957, 1962, 1965a, 1965b, 1971, 1986, 1987, 1992, 1996), até outros teóricos, como John Bolwby $(1969,1982)$ com sua teoria sobre o vínculo e Daniel Stern $(1977,1985,1997)$, com seus estudos sobre a subjetividade do bebê.

As intervenções psicoterápicas pais/bebê também tiveram suas origens nos trabalhos de Mahler (1973), com mães psicóticas, de Fraiberg, Adelson e Shapiro (1975) e Fraiberg (1980), com mães provenientes de meios sociais desfavorecidos, e de Ainsworth (1969, 1985), com suas pesquisas sobre apego. Um grande impulso ocorreu com os estudos de Cramer (1974, 1987, 1988, 1989, 1997, 1999), Cramer e Palácio-Espasa (1993) e de Lebovici (1983, 1991, 1992, 1994, 1996, 1998a, 1998b, 2003) e colaboradores (Golse, 1998; Guedeney \& Lebovici, 1999; Mazet, 1994; Mazet, CukierHemeury, Latoch, Rosenblum, \& Sitbon, 1989; Mazet \& Stoleru, 1990; Solis-Poton, 2002).

A noção de mutualidade psíquica pais/bebê proposta por Cramer (1974) modificou a compreensão dos sintomas no 
bebê, e conduziu a uma valorização das influências dos aspectos fantasmáticos dos pais na organização psíquica da criança. A importância fundamental do mandato transgeracional desenvolvida por Lebovici (1983, 1996 e 1998b) ampliou a compreensão quanto à influência da dinâmica das famílias de origem dos pais nas interações pais/criança.

Quando os pais procuram um psicólogo ou psicanalista porque algo não está bem com seu bebê, na maioria das vezes já passaram por atendimento médico, em geral pelo pediatra, e não encontraram uma solução para suas preocupações. Nesses casos, deve-se investigar as queixas trazidas pelos pais, que, freqüentemente, estão relacionadas a uma série de manifestações somáticas ou do comportamento do bebê, que podem ser denominadas sintomas psicofuncionais.

Assim, os distúrbios psicofuncionais são manifestações de natureza principalmente somática e do comportamento da criança, sem causa orgânica, que estão associadas a um determinismo psicológico, e sinalizam, de forma geral, dificuldades na interação mãe/bebê ou pais/bebê.

Os distúrbios psicofuncionais mais freqüentes na fase inicial de vida são: (a) distúrbios de sono, como a criança que dorme mal, acorda muitas vezes durante a noite, demora para dormir, vai dormir muito tarde, dorme pouco ou demais para a idade, não tem horário na sua rotina de sono, etc.; (b) distúrbios alimentares na quantidade ou na qualidade da alimentação, dificuldades com tipos específicos de alimentos que devem ser introduzidos ao longo do primeiro ano de vida; (c) distúrbios digestivos e gástricos, como regurgitação, cólica, soluço, prisão de ventre, diarréia, etc.; (d) distúrbios respiratórios, tais como asma, bronquite, alergias respiratórias e infecções de repetição como faringites, laringites, etc.; (e) problemas de pele, como eczema e alergias cutâneas; e (f) distúrbios de comportamento, por temperamento difícil, irritação e choro freqüentes, baixa consolabilidade, ansiedade e medo constantes, dificuldades de vínculo ou de separação, etc.

A importância de se considerar e se avaliar os distúrbios psicofuncionais, numa faixa etária precoce, se justifica pela possibilidade de uma intervenção que seja ao mesmo tempo curativa, isto é, que atue na redução ou no desaparecimento dos sintomas, alivie a ansiedade, a preocupação e o sofrimento que, em geral, estão associados, mas, também, seja preventiva quanto aos possíveis agravamentos e ao surgimento de distúrbios crônicos futuros.

Deve-se, também, considerar preventivamente as situações e interações de alto risco: no caso de crianças que apresentam deficiências, crianças filhas de pais $\mathrm{HIV}^{+}$(cujo número vem aumentando consideravelmente em nossa população), crianças nascidas prematuramente (Batista Pinto, Graham, Igert, \& Solis-Poton, 2002), ou que viveram intervenções médicas no período neonatal, ou ainda problemas relativos à mãe; por exemplo, depressão, psicose pós-parto ou outros transtornos psíquicos, morte ou doença grave da mãe após o parto e fatores associados.

Nesses casos de risco, pode ser interessante fazer um seguimento em psicoterapia pais/bebê durante o primeiro ano de vida da criança, e realizar o acompanhamento do desenvolvimento do bebê utilizando, por exemplo, a Escala de De- senvolvimento do Comportamento no Primeiro Ano de Vida - EDC (Batista Pinto, Vilanova, \& Vieira, 1997).

Em qualquer fase é fundamental que se conheça bem como se dá o funcionamento do comportamento da criança e o que se pode esperar em sua faixa etária, compreendendo a mesma dentro de seu contexto geral e de seu ambiente próximo, isto é, sua dinâmica familiar, levando-se em conta que esta se estabelece a partir de circunstâncias e situações do presente, assim como da sua história de vida e da história de vida de seus pais.

Considerando-se o comportamento como manifestação da subjetividade humana, pode-se avaliar na criança, desde bebê, qual a qualidade da atenção que ela tem para o mundo que a cerca, o tipo de temperamento e de humor que expressa as atividades que prefere, suas reações frente aos estímulos e às modificações do ambiente, sua modalidade de apego e a relação que estabelece com as figuras parentais, seu limiar e o nível de responsividade às solicitações e estímulos externos, suas condições psicológicas atuais e sua disponibilidade para a interação.

A investigação deve incluir o tipo de sintoma que a criança apresenta, sua intensidade e freqüência, sua história e os processos relacionados, os aspectos preservados da interação com a mãe, o pai e outros familiares, as representações materna e paterna e o mandato transgeracional.

Por exemplo, um bebê pode ter um limiar de estimulação alto e necessitar de mais estímulos para reter sua atenção, outro pode ser tão sensível aos estímulos que estes desencadeiam reações de susto, outro pode cansar-se rapidamente da estimulação e passar a ter comportamentos de esquiva como olhar para outro lado, fechar os olhos, etc.

Sabe-se que nos primeiros meses de vida da criança há uma série de manifestações somáticas e do comportamento que são próprias da faixa etária e necessitam de um período para atingirem uma boa regulação. Espera-se que o bebê possa, com o tempo, regular seus estados de sono/vigília, fome/ saciação, atenção/habituação e atividade/repouso. É evidente que os parâmetros de comportamento vão se modificando com a passagem dos meses, mas também sofrem a influência do ambiente próximo e de características individuais da criança (Batista Pinto et al., 1997).

Para a avaliação dos sintomas psicofuncionais da criança, Robert-Tissot, Rusconi-Serpa, Bachman, Besson, Cramer, Knauer, Muralt e Palacio-Espasa (1989) propuseram um roteiro de entrevista a ser realizado com a mãe - a Symptom CheckList - que se mostra útil, principalmente, na clínica e na pesquisa.

Se a interação é um dos principais focos de nosso interesse, é fundamental que se possa conhecê-la e compreendêla da forma mais ampla possível. A interação está em estreita relação com as representações materna e paterna com respeito à criança, e, como resultado, as representações costumam ser diferentes para cada um dos pais e para cada filho, porque cada criança nasceu em um determinado momento da história de vida da mãe e do pai, tendo significados que lhe são específicos e diferentes dos outros filhos que eles possam ter tido ou vir a ter. 
Por representações parentais consideram-se as fantasias, os temores, os desejos, as percepções mais seletivas, as identificações, os pensamentos, os sentimentos e as atribuições que a mãe e o pai têm em relação à criança.

As representações que envolvem elementos inconscientes têm uma influência fundamental na interação, e tanto podem ser constituídas por elementos positivos, que favoreçam a elaboração e a resiliência, como também podem ser patogênicas e determinarem uma interação patológica e o aparecimento de distúrbios psicofuncionais.

As representações materna e paterna, portanto, são modeladas a partir das experiências diárias da mãe e do pai, da sua dinâmica como casal e como fundadores da sua família atual, mas, também, da dimensão transgeracional. Esta dimensão engloba os conflitos que estão associados às gerações anteriores, e que vão, de forma inconsciente, determinar comportamentos e interações atuais. Este é o que Lebovici (1996, 1998b) nomeou como mandato transgeracional.

Assim, considerando-se que as bases da subjetividade da criança são construídas a partir dos seus primeiros vínculos, e que os sintomas psicofuncionais indicam dificuldades na interação com os pais, o foco de nossa análise deve ir além das especificidades do distúrbio apresentado pela criança e deter-se detalhadamente nas interações.

Portanto, ao se conduzir uma consulta terapêutica com os pais, é muito importante investigar quais as fantasias e expectativas com relação à criança, como eles percebem a si próprios como pessoas e como pais, como percebem seu cônjuge na interação, como percebem seus próprios pais enquanto pessoas e pais, e quais as modificações em suas relações com seus pais a partir do nascimento da criança.

Também é importante investigar qual o apoio que a mãe e a criança recebem tanto do pai como de suas famílias e outros membros e organização da comunidade.

$\mathrm{Na}$ investigação dos aspectos transgeracionais da interação, além da entrevistas clínicas, pode ser utilizado um instrumento bastante rico, especialmente para pesquisas, que é o roteiro Entretien - $R$ elaborado pelo grupo da Universidade de Genebra (Stern et al., 1989).

Já na observação das interações precoces nas consultas terapêuticas, o foco principal deve ser a mãe e o pai e seu modo de estar com a criança, considerando-se três eixos de análise: o comportamental, o afetivo e o fantasmático, que inclui o mandato transgeracional.

Nessa observação consideram-se tanto os aspectos conscientes - falas, queixas e informações trazidas pelos pais - como os inconscientes, que vão exigir do terapeuta um olhar mais atento, e que, em geral, são observados nos elementos mais sutis dos comportamentos materno e paterno, e que seriam uma tradução em ação das suas representações.

A análise da interação familiar deve incluir a forma como a mãe e o pai estimulam o bebê - excesso ou falta de estimulação - o tipo de reciprocidade e sincronicidade que se estabelece (por exemplo se a mãe espera o ritmo do bebê ou é muito ansiosa, atropela a criança e não lhe dá tempo para ela reagir); como negociam frente às dificuldades e conflitos; e se permitem uma transformação na interação de acordo com o desenvolvimento da criança, ou a relação fica como que congelada em uma fase muito anterior, ou ao contrário, envolve um nível de exigência ao qual a criança não é capaz de corresponder.

Por outro lado, quando se observa a interação precoce, também se deve observar o comportamento do bebê: suas iniciativas e recusas, os conflitos que mostra na interação, como se aproxima e se esquiva, os tipos de brincadeira que faz, como reage às negociações propostas pelo adulto, enfim toda a sua forma de interagir com a mãe e o pai.

As possibilidades dos pais de preverem as transformações da criança também são elementos importantes nos ajustes da interação, isto é, a sua capacidade de antecipação das modificações que o crescimento e o desenvolvimento implicam, seja no nível das mudanças de alimentação, sono, comportamento, atividades, etc.

No plano afetivo, é importante considerar os sentimentos que surgem na interação, sejam eles verbalizados ou expressos através do comportamento, assim como os graus de ansiedade, insegurança, agressividade, erotização, etc.

Partindo-se dos aspectos comportamentais para uma análise dos elementos mais sutis da interação, podem-se obter informações sobre aspectos relativos às representações maternas, sendo importante observar, na troca interativa, todas as manifestações de subjetividade: expressões faciais, expressões vocais, posição e contato corporal - tanto físico como cutâneo - comportamento afetivo, tipo de vocalização e em que momento ocorre, comunicação em termos de entonação, linguagem, conteúdo e ritmo das trocas interativas.

Também são importantes os indícios da qualidade da interação, tais como o nível de sensibilidade que o adulto mostra com relação ao comportamento da criança, a interpretação que dá aos sinais da criança assim como às suas respostas.

No aspecto fantasmático devem ser consideradas as expectativas dos pais com relação à criança, por exemplo, no caso de famílias de migrantes pode haver uma grande expectativa depositada no filho que nasce, de que ele desempenhe o papel de inserir a sua família no grupo social que os pais escolheram para viver. Isso pode ser uma situação de risco para a interação, no caso de a criança não se mostrar com condições de desempenhar bem o papel que lhe foi atribuído pela família, por exemplo, por apresentar dificuldades de desenvolvimento ou de aprendizagem.

Todas essas observações e análises podem permitir que se conheça melhor as relações entre os elementos da interação, o tipo de apego estabelecido entre o bebê e seus pais, o comportamento e os distúrbios psicofuncionais do bebê.

Quando se consideram os padrões de apego propostos por Ainsworth $(1969,1985)$, diante da separação breve a criança pode mostrar:

Apego seguro. Quando a criança demonstra uma boa experiência de interação. A mãe mostra-se bem coordenada, sensível e é raramente super-estimuladora, sendo capaz de reestabilizar as respostas emocionais desorganizadas da criança. Na presença da mãe a criança explora o ambiente e evita pessoas estranhas. Na ausência, mesmo breve, da mãe, a criança fica perturbada e busca contato ao retorno materno. 
Apego ansioso/evitativo. Quando a ativação emocional da criança não é reestabilizada pela mãe e a criança é superestimulada por condutas parentais intrusivas, ela pode regular seus afetos evitando situações sentidas como perturbadoras. Na presença da mãe a criança explora o ambiente, mas não se mostra muito ansiosa com a separação breve e pode não buscar contato ao retorno desta ou mesmo preferir o contato com uma pessoa estranha. Por exemplo, a mãe super-estimuladora pode ser invasiva, estabelecer um ritmo precipitado ou muito forte que o bebê tenta de todo modo reduzir, seja desviando o olhar, cochilando, etc. O bebê tende a apresentar ou um apego excessivo ou uma esquiva ativa. Em casos de persistência de uma intensidade de estimulação que o bebê não consegue acompanhar, este tende a desenvolver distúrbios de sono ou distúrbios digestivos como cólicas, espasmos de glote ou soluços.

Apego ansioso/resistente. Quando a criança mostra um baixo limiar frente às situações que sente como ameaçadoras, e se mostra frustrada inclusive quando o contato está disponível, fazendo tentativas para despertar uma resposta da mãe. $\mathrm{Na}$ presença da mãe a criança explora o ambiente, mas fica muito perturbada na separação breve da mãe, e pode mostrar agitação, tensão e dificuldades para se organizar. A presença da mãe e suas tentativas para acalmá-lo fracassam e a ansiedade e raiva da criança podem impedi-la de obter alívio mesmo com a presença materna. Quando a mãe sub-estimula, não reage aos sinais do bebê, não responde ao que o bebê precisa, e, ao contrário, o bebê busca o contato e a estimulação, mas sem encontrar correspondência, podem surgir distúrbios alimentares como a anorexia ou digestivos como a regurgitação, os vômitos etc. que poderiam estar associados à ausência de interação materna.

Apego desorganizado/desorientado. Quando a criança manifesta comportamentos sem um fim aparente, tem maneirismos, balanceios de cabeça, etc., demonstrando o desejo de escapar da situação. Em geral, revela uma relação ambivalente com a mãe, motivada por graves conflitos. Neste caso, podem surgir distúrbios psicopatológicos mais graves, como comportamentos autísticos.

Como o modelo de apego estabelecido pela criança no início de sua vida serve de protótipo para as suas relações ulteriores e é relativamente estável ao longo do ciclo vital (Lebovici, 1996), há uma tendência à persistência transgeracional, isto é, a uma perpetuação do modelo de apego de uma geração à outra.

É muito interessante que se possam diagnosticar e tratar precocemente os sintomas psicofuncionais, pois estes podem, mais tarde, se desenvolver e aparecer de forma muito mais grave, por exemplo, no caso de anorexia, colites, etc.

Assim, o que se propõe nesses casos é o atendimento terapêutico da díade mãe/bebê ou da tríade mãe-pai/bebê, em psicoterapia breve com foco na interação, de modo que os conflitos relativos à maternagem e à paternagem, até mesmo aqueles referentes ao mandato transgeracional, possam ser trabalhados e superados.

Portanto, a intervenção psicológica precoce na dinâmica familiar (Batista Pinto, 2000), que possibilita tanto a detecção como o tratamento de conflitos relativos à maternagem e à paternagem, pode contribuir para o estabelecimento de vínculos saudáveis, favorecer o desenvolvimento da criança e prevenir o aparecimento ou a manutenção de distúrbios sintomas psicofuncionais ou outras psicopatologias.

\section{Luiz: o alimento e a vida}

Luiz veio a uma consulta terapêutica no Hospital Universitário da Universidade de São Paulo com um mês e meio de vida. Nasceu sem problemas, de parto natural, a termo, com peso de $3.365 \mathrm{~g}$ e estatura de $48 \mathrm{~cm}$. Foi encaminhado para a psicóloga pela equipe de enfermagem, pelo fato de ser amamentado ao seio, sem dificuldades aparentes, mas não estar adquirindo peso. $\mathrm{Na}$ ocasião pesava $3.420 \mathrm{~g}$.

Na primeira sessão, a mãe de Luiz contou que era divorciada havia 3 anos, considerava que seu casamento havia sido bom e tinha outras duas filhas, de 9 e 4 anos. Sua primeira gravidez foi acidental, antes do casamento, e a segunda gravidez foi planejada. Separou-se devido ao marido ter outro relacionamento. Após a separação, o pai de suas filhas constituiu outra família, mas provia pensão às filhas do casal.

A gravidez de Luiz foi casual, fruto de um breve relacionamento. A mãe só teve a certeza de estar grávida aos 3 meses de gestação e o pai de Luiz não assumiu a sua paternidade. O pai soube do nascimento de Luiz, mas não foi visitá-lo, sendo a criança registrada apenas com o sobrenome da mãe.

A mãe ocultava de sua família a situação que estava vivendo, referindo que seus pais souberam da gestação de Luiz apenas no final, mas julgavam, erroneamente, que ela tivesse um novo companheiro. Também o ex-marido não aceitou bem esta gravidez, ameaçando interromper o pagamento da pensão que dava às filhas, pois "não ia sustentar filho de outro" (sic).

Quanto à amamentação, a mãe relatou que sentia os seus seios machucados, pois Luiz queria mamar "todo o tempo" (sic). Sua primeira filha foi amamentada por quatro meses, mas a segunda, que nasceu prematura, aos oito meses de gestação, não foi amamentada ao seio.

$\mathrm{Na}$ primeira sessão, enquanto a mãe de Luiz fazia seu relato, observou-se que ela estava deprimida, muito angustiada e temerosa por sua situação. Seus conflitos estavam associados principalmente ao pai de Luiz e ao seu futuro. Se, por um lado, considerava importante que o pai do menino o assumisse legal e afetivamente, por outro achava que isto deveria ser espontâneo. Sentia-se também muito triste pelo abandono do namorado e por não contar com apoio familiar.

Quanto indagada sobre o bebê, a mãe relatou que ele era "bonzinho", "chorava só para mamar" (sic), mostrando-se afetiva e vinculada. Nesta primeira sessão, trabalhou-se terapeuticamente a decepção e luto da mãe com o término do relacionamento com o namorado e suas possibilidades de apego e interação com o bebê.

$\mathrm{Na}$ segunda sessão, Luiz tinha dois meses e cinco dias. A mãe mostrava-se bem mais tranqüila e sorridente. Era muito afetuosa com o bebê, que estava muito bem cuidado e a olhava com insistência. Relatou que havia ido à casa de seus pais para apresentar-lhes o bebê. Diariamente passeava com Luiz 
na área comum do prédio onde residia. Continuava amamentando ao seio e Luiz pesava $5.320 \mathrm{~g}$ e tinha $57 \mathrm{~cm}$. A mãe sentia-se mais forte emocionalmente por estar superando as dificuldades e por Luiz estar se desenvolvendo bem.

Por ocasião da terceira sessão, Luiz estava com três meses e dois dias. A irmã mais nova veio junto com ele e a mãe, mostrando-se por um lado afetiva e, por outro, ciumenta e carente de atenção. Ela dormia na cama da mãe desde a separação dos pais; Luiz dormia no berço no mesmo quarto e a irmã mais velha em outro quarto. $\mathrm{O}$ desenvolvimento global de Luiz era excelente. Era um bebê muito ativo, sorridente, comunicativo e muito ligado à mãe. Seu peso era acima da média para a idade (7.500 g). Apresentava uma alergia de pele com manchas avermelhadas na barriga, nas pernas e pés.

Aos quatro meses a alimentação de Luiz ainda se restringia única e exclusivamente à amamentação ao seio, não aceitando nem mesmo suco ou chá. A alergia de pele localizavase no peito. A mãe havia escrito uma carta ao pai de Luiz e marcado um encontro. Tinha sentimentos ambivalentes de amor e raiva para com o ex-namorado. Tinha dúvidas sobre levar ou não Luiz no encontro com o pai. Na consulta, tais sentimentos e conflitos foram trabalhados.

Aos cinco meses havia sido introduzida a alimentação pastosa - sopinha e frutas -, mas a amamentação ao seio continuava em outros horários. Os avós maternos estavam bem mais próximos e a mãe fazia questão de afirmar que o bebê começava a estranhar a presença de outras pessoas, mas não a dos avós. A alergia de pele restringia-se mais ao contato com lã, e estava sendo tratada com cremes específicos. A mãe havia voltado a estudar, fazendo supletivo à noite. Havia se encontrado com o pai de Luiz, mas não havia levado o bebê. Contou sobre seus sentimentos com relação ao pai de Luiz, ao reencontro, e a ter tomado conhecimento de que ele tinha uma namorada.

Aos seis meses, Luiz prosseguia desenvolvendo-se bem. Era um bebê forte, de ótimo humor. A alergia de pele ia e voltava. A mãe havia tido uma audiência do processo de pensão do ex-marido e estava tentando cuidar da situação. Luiz tinha conhecido seu pai e ficado bem em sua companhia. $\mathrm{O}$ pai estava se interessando e telefonando para saber notícias dele. Na sessão a mãe referiu que Luiz "já conhece seu próprio nome" (sic).

Com sete meses, Luiz veio para a sessão com febre e indisposto. Tinha dois dentinhos em erupção. Sua alergia de pele havia piorado e o médico estava restringindo o tipo de alimentação. Tinha algumas dificuldades para dormir. O seu desenvolvimento era excelente e estava muito apegado à mãe, não aceitando outras pessoas. A mãe mostrava-se bastante segura e paciente.

Com oito meses, Luiz teve otite. Continuava sendo amamentado e dormindo no mesmo quarto da mãe, mas esta havia conseguido mudar a filha para o quarto junto com a irmã. Luiz tinha começado a engatinhar.

Aos nove meses, Luiz estava bem, ativo, com ótimo humor. A mãe havia associado sua alergia a alimentos que continham corantes. Pesava mais de dez quilos. Sua mãe, por outro lado, estava muito triste, vivendo nova decepção com a falta de contato do pai de Luiz. Buscava elaborar e superar a situação estando decidida a não procurá-lo.

Luiz, com dez meses, continuava muito ativo. Sua mãe havia terminado o curso supletivo e viajado alguns dias com as crianças para a praia. O pai de Luiz havia telefonado e prometido ir vê-lo, mas não cumpriu a promessa. A mãe mostrava-se paciente e conformada com a situação.

Aos onze meses Luiz era muito apegado às irmãs e à mãe. Ágil, atento, parecia compreender muito do que se falava. Ainda mamava, mas o processo de desmame estava sendo iniciado. Dormia bem. A mãe estava mais sociável e tinha novas amizades. Referia estar aos poucos esquecendo do pai de Luiz e refazendo sua vida. As férias tinham acabado e ela pretendia prosseguir os estudos. Mostrava-se tranqüila e mais estabilizada emocionalmente.

Luiz, aos doze meses, dava alguns passinhos sozinho, falava "mãe" e apontava para mostrar o que queria. Dormia bem, comia de tudo e ainda era amamentado duas vezes ao dia ao seio. A alergia de pele havia desaparecido. Era uma criança sociável e calma. Sua mãe sentia-se bem emocionalmente há alguns meses. Estava adaptando Luiz na creche, pois ia recomeçar a trabalhar. Tinha se decidido a abrir o processo de paternidade e defender os direitos de Luiz de ter o nome do pai.

Nosso trabalho podia ser encerrado. Ao realizarmos a preparação para o desligamento, nos referimos ao fato dela estar cuidando bem de sua vida, sentir-se mais estabilizada emocionalmente, e de Luiz já ter um ano e ter superado os sintomas que apresentava. Em resposta, ela nos disse: "Nós estamos mesmo muito bem, mas foi um longo caminho, e eu pude contar com o seu apoio para me ajudar a superar as dificuldades" (sic).

\section{Considerações finais}

O caso de Luiz pareceu-me interessante de ser descrito, pois ilustra bem a relação entre os sintomas psicofuncionais do bebê, suas dificuldades iniciais de alimentação e, posteriormente, sua alergia de pele, e as dificuldades da mãe diante de uma situação socialmente complexa e emocionalmente muito difícil.

O fato de Luiz não ser uma criança de risco, do ponto de vista orgânico, nos permitiu ainda com maior facilidade, focar as questões psicológicas associadas à gestação e ao nascimento, e que formam as bases para a interação inicial. É um bom exemplo do conceito de mutualidade psíquica (Cramer, 1974) entre o bebê e a mãe, segundo o qual, mesmo recebendo o alimento, o bebê teve seu desenvolvimento físico comprometido em função da depressão materna e da sua falta de energia psíquica na interação.

A substituição de um distúrbio alimentar por um distúrbio de pele também pode ser interpretada como um sinal de evolução, na medida em que o primeiro é muito mais grave, podendo comprometer até a vida da criança, e o segundo permite um foco mais específico no contato, e no caso, não apresentava maior gravidade.

A interação entre Luiz e sua mãe pôde ser construída de forma segura, e a mãe mostrou-se sensível, respondendo ao 
bebê de modo harmonioso. Os recursos psicológicos da mãe e sua capacidade de resiliência foram elementos importantes nesse processo, mas também a capacidade do bebê de parentalizar a mãe (Lebovici, 1998b). As consultas terapêuticas favoreceram essa parentalização, podendo a terapeuta ser sentida como uma "mãe suficientemente boa" para acolher a díade e impulsionar sua busca de inserção e aceitação familiar e social. O trabalho terapêutico pôde ser especialmente frutífero na transformação do bebê fantasmático, do bebê imaginário e sua aceitação como bebê real, com suas características e sua história sempre peculiares.

Foi o processo de parentalização que também permitiu à mãe lutar pelo "nome do pai” e por seu reconhecimento como porta-voz dos direitos da criança. Assim foi sendo construído o duplo processo de filiação e de parentalização.

\section{Referências}

Ainsworth, M. D. S. (1969). Object relations, dependency and attachment: a theoretical review of the infant-mother relationship. Child Development, 40 , 969-1025.

Ainsworth, M. D. S. (1985). Attachments across the lifespan. Bulletin of the New York Academy of Medicine, 61, 792-812.

Batista Pinto, E., Vilanova, L. C. P., \& Vieira, R. M. (1997). O desenvolvimento do comportamento da criança no primeiro ano de vida: padronização de uma escala para a avaliação e o acompanhamento. São Paulo: FAPESP/ Casa do Psicólogo.

Batista Pinto, E. (2000). Psicoterapia breve mãe/bebê. In C. F. Rohenkohl (Org.), A clínica com o bebê (pp. 125-130). São Paulo: Casa do Psicólogo.

Batista Pinto, E., Graham, S., Igert, B., \& Solis-Poton, L. (2002). Les enjeux de la parentalité avec l'enfant prématuré. In L. Solis-Poton (Org.), La parentalité: défi pour le troisième millénaire (pp. 273-295). Paris: Presses Universitaires de France.

Bowlby, J. (1969). Attachment and loss (Vol. 1). Londres: Hogarth.

Bowlby, J. (1982). Formação e rompimento dos laços afetivos. São Paulo: Martins Fontes.

Cramer, B. (1974). Interaction réelle et interaction fantasmatique. Réflexion au sujet des thérapies et des observations du nourisson. Psychothérapies, 1 , 39-47.

Cramer, B. (1987). Objective and subjective aspects of parent-infant relations: an attempt at correlation between infant studies and clinical work. In J. D. Osofsky (Org.), Handbook of infant development (pp. 1037-1057). Nova York: Wiley.

Cramer, B. (1988). Psychiatrie du bébé, nouvelles frontières. Paris/Genève: Eshel.

Cramer, B. (1989). Proféssion: bébé. Paris: Calman-Lévy.

Cramer, B. (1997). Segredos femininos: de mãe para filha. Porto Alegre: Artes Médicas.

Cramer, B. (1999). Técnica das terapias breves pais/crianças pequenas. In A. Guedeney \& S. Lebovici (Orgs.), Intervenções psicoterápicas pais/bebê. Porto Alegre: Artes Médicas.

Cramer, B., \& Palacio-Espasa, F. (1993). Técnicas psicoterápicas mãe/bebê: estudos clínicos e técnicos. Porto Alegre: Artes Médicas.

Fraiberg, S. (1980). Clinical studies in infant mental health: the first year of life. Nova York: Basic Books.

Fraiberg, S., Adelson, E., \& Shapiro, V. (1975). Ghosts in the nursery: a psychoanalytic approach to the problems of impaired mother-infant relationships. Journal of the American Academy of Child Psychiatry, 14, 387-421.

Freud, S. (1976). Obras psicológicas completas. Rio de Janeiro: Imago.
Golse, B. (1998). Attachement, modèles opérants internes et métapsychologie, ou comment ne pas jeter l'eau du bain avec le bébé. In A. Braconnier \& J. Sipos (Orgs.), Le bébé et les interactions précoces (pp. 149-165). Paris: Presses Universitaires de France.

Guedeney, A., \& Lebovici, S. (1999). Intervenções psicoterápicas pais/bebê. Porto Alegre: Artes Médicas.

Klein, M. (1923). The development of a child. International Journal of Psycho Analysis, 4, 419-474.

Klein, M. (1927). The psychological principles of infant analysis. International Journal of Psycho Analysis, 8, 25-37.

Klein, M. (1928). Early stages of the oedipus conflict. International Journal of Psycho Analysis, 9, 167-180.

Klein, M. (1929a). Infantile anxiety-situations reflected in art, creative impulse. International Journal of Psycho Analysis, 10, 436-443.

Klein, M. (1929b). Personification in the play of children. International Journal of Psycho Analysis, 10, 193-204.

Klein, M. (1930). The importance of symbol-formation in the development of the ego. International Journal of Psycho Analysis, 11, 24-39.

Klein, M. (1945). The oedipus complex in the light of early anxieties. International Journal of Psycho Analysis, 26, 11-33.

Klein, M. (1952). The mutual influences in the development of ego and id. Psychoanalytic Study of the Child, 7, 51-53.

Klein, M. (1958). On the development of mental functioning. International Journal of Psycho Analysis, 39, 84-90.

Lebovici, S. (1983). Le bébé, la mère et le psychanalyste: les interactions precoces. Paris: Le Centurion.

Lebovici, S. (1991). A propos du travail de René Zazzo "l'attachement" quelques réflexions d'un psyhcanalyste. In R. Zazzo (Org.), “L'attachement” (pp. 79-84). Neuchâtel: Delachaux et Niestlé.

Lebovici, S. (1992). La théorie de l'attachement et la métapsychologie freudienne. Devenir, 4(4), 33-48

Lebovici, S. (1994). L'homme dans le bébé. Revue Française de PsychanalyseI, $\operatorname{LVIII(3),~661-680.~}$

Lebovici, S. (1996). La transmission intergénérationnelle ou quelques considérations sur l'utilité de l'étude de l'arbre de vie dans les consultations thérapeutiques parents/bébé. In M. Dugnat (Org.), Troubles relationnels père-mère/bébé: quels soins? (pp. 19-28). Ramonville St Agne: Érès.

Lebovici, S. (1998a). Lettre ouverte à Robet Emde et réponse à ses questions concernant l'empathie. In A. Braconnier \& J. Sipos (Orgs.), Le bébé et les interactions précoces. (pp. 9-26). Paris: Presses Universitaires de France.

Lebovici, S. (1998b). L'arbre de vie. Journal de psychanalyse de l'enfant. Les psychothérapies psychanalytiques, 221, 98-127.

Lebovici, S. (2003). Consultation mère-nourrisson. In C. Geissmann \& D. Houzel (Org.), L'enfant, ses parents et le psyhcanalyste. Paris: Bayard Compact.

Mahler, M. (1973). Psychose infantile. Paris: Payot.

Mazet, P. (1994). Un bébé de plus en plus présent. Synapse, 103, 45-51.

Mazet, P., Cukier-Hemeury, F., Latoch, J., Rosenblum, O., \& Sitbon, H. (1989). Étude historique et critique. In S. Lebovici, P. Mazet \& J.-P. Visier (Orgs.), L'évaluation des interactions précoces entre le bébé et ses partenaires (pp.15-39). Paris: Eshel.

Mazet, P., \& Stoleru, S. (1990). Manual de psicopatologia do recém-nascido. Porto Alegre: Artes Médicas.

Robert-Tissot, C., Rusconi-Serpa, S., Bachman, J.-P., Besson, G., Cramer, B., Knauer, D., Muralt, M. de, \& Palacio-Espasa, F. (1989). Le questionnaire "Sympton Check-List". In S. Lebovici, P. Mazet, \& J.-P. Visier (Orgs.), L'évaluation des interactions précoces entre le bébé et ses partenaires (pp. 179-186). Paris: Eshel.

Solis-Poton, L. (2002). La parentalité: défi pour le troisième millénaire. Paris, Presses Universitaires de France.

Stern, D. N. (1977). The first relationship infant and mother. Cambridge: Harvard University Press. 
Stern, D. N. (1985). The interpersonal world of the child. A view from psychoanalysis and developmental psychology. Nova York: Basic Books.

Stern, D. N., Robert-Tissot, C., Besson, G., Rusconi-Serpa, S., Muralt, M. de, Cramer, B., \& Palacio-Espasa, F. (1989). L'entretien "R": une méthode d'évaluation des representations maternelles. In S. Lebovici, P. Mazet, \& J.P. Visier (Orgs.), L'évaluation des interactions précoces entre le bébé et ses partenaires (pp. 151-160). Paris: Eshel.

Stern, D. N. (1997). A constelação da maternidade: o panorama da psicoterapia pais/bebê. Porto Alegre: Artes Médicas.

Winnicott, D. W. (1931). Clinical notes on the disorders of childhood. Londres: William Heinemann.

Winnicott, D. W. (1941). The observation of infants in a set situation. International Journal of Psycho Analysis, 22, 229-249.

Winnicott, D. W. (1942). Child department consultations. International Journal of Psycho Analysis, 23, 139-146.

Winnicott, D. W. (1945). Primitive emotional development. International Journal of Psycho Analysis, 26, 137-143.
Winnicott, D. W. (1953). Transitional objects and transitional phenomena; a study of the first not-me possession. International Journal of Psycho Analysis, 34:89-97.

Winnicott, D. W. (1957). Mother and child. A primer of first relationships. Nova York: Basic Books.

Winnicott, D. W. (1962). The theory of the parent-infant relationship: further remarks. International Journal of Psycho Analysis, 43, 238-239.

Winnicott, D. W. (1965a). Maturational processes and the facilitating environment. Londres: Hogarth.

Winnicott, D. W. (1965b). Failure of expectable environment on child's mental functioning. International Journal of Psycho Analysis, 46, 81-87.

Winnicott, D. W. (1971). Therapeutic consultations in child psychiatry. Londres: Hogarth.

Winnicott, D. W. (1986). Holding and interpretation. Londres: Hogarth.

Winnicott, D. W. (1987). Babies and their mothers. Londres: Free Association.

Winnicott, D. W. (1992). The family and individual development. Londres: Routledge.

Winnicott, D. W. (1996). Thinking about children. Londres: Karnac.

Notas

1 Palestra apresentada na Jornada de Diagnóstico Psicológico do Departamento de Psicologia Clínica do Instituto de Psicologia da Universidade de São Paulo, em São Paulo, em 25 de setembro de 1999.

2 O grande interesse que esses temas têm despertado em nosso meio motivou a criação do Curso de Especialização à Distância em Psicopatologia do Bebê, que coordenei em 2000/2001 juntamente com Eva Maria Migliavacca, no Departamento de Psicologia Clínica do Instituto de Psicologia da Universidade de São Paulo, em cooperação com a Universidade Virtual Euro-América (com sede no México) e a Universidade de Paris XIII.

Elizabeth Batista Pinto, doutora em Distúrbios da Comunicação Humana (Fonoaudiologia) pela Universidade Federal de São Paulo, é professora no Departamento de Psicologia Clínica do Instituto de Psicologia da Universidade de São Paulo. Endereço para correspondência: Gouverneur van der Fossestraat 2; 5224 CG; 's-Hertogenbosch; Holanda. Tels.: 0031736891410 ou 003161393 7474. E-mail: ebatista@usp.br 